\title{
A framework for designing and improving learning environments fostering creativity
}

\author{
Learning environments fostering creativity
}

\author{
Norio Ishii \\ Yuri Suzuki \\ Hironobu Fujiyoshi \\ Takashi Fujii \\ Masanori Kozawa
}

\begin{abstract}
This paper proposes a framework for designing and improving learning environment for creativity in engineering. The framework consists of the following three components: instructional design based on knowledge from psychology, development of systems for supporting creative activities, and objective evaluation of learning results related to creativity. Based on that framework, we design and practice course based in the programation of a robot at a Japan University in the 2004 academic year. As a result, we confirm the following two advantages of our framework: learners' idea generation skills were improved and their meta-cognitive activities were also activated. In the 2005 academic year, we improve the course based on 2004 results. As a result, we confirm that the number of uploads of activity data from students have increased in the 2005 course, students' reflection sheets have become more detailed, and their volume of information have also increased.
\end{abstract}

Keywords: Creativity; Knowledge; Learning.

\section{Uma estrutura para projetar e implementar meios criativos de aprendizagem}

\section{Resumo}

Esse artigo propõe uma estrutura para projetar e implementar meios de aprendizagem da criatividade na engenharia. A estrutura é composta por três componentes: modelos instrucionais baseados no conhecimento da psicologia, desenvolvimento de sistemas para apoiar atividades criativas e avaliação objetiva de resultados relacionados com a criatividade no aprendizado. Baseado nessa estrutura, projetou-se e testou-se um curso baseado na programação de um robô em uma Universidade Japonesa em 2004. Como resultado, confirmaram-se duas vantagens da estrutura escolhida: a habilidade dos estudantes para gerar idéias foi ampliada e ativaram suas habilidades metacognitivas. No ano de 2005, o curso foi estruturado e implementado a partir dos resultados observados no curso de 2004. Como resultado final, confirmou-se que o número de atividades realizadas pelos alunos cresceu no curso de 2005. Os relatórios dos alunos se tornaram mais detalhados, com maior quantidade de informações descritas neles. Palavras chave: Criatividade; Conhecimento; Aprendizagem.

\section{Una estructura para proyectar e implementar medios creativos de aprendizaje}

\section{Resumen}

Este artículo propone una estructura para proyectar e implementar medios de aprendizaje de la creatividad en ingeniería. La estructura es formada por tres componentes: modelos institucionales basados en el conocimiento de la psicología, desarrollo de sistemas para apoyar actividades creativas y evaluación objetiva de resultados relacionados con la creatividad en el aprendizaje. Basado en esa estructura se proyectó y examinó un curso basado en la programación de un robot en una Universidad Japonesa en el 2004. Como resultado se confirmaron dos ventajas de la estructura elegida: la habilidad de los estudiantes para generar ideas fue ampliada y activaron sus habilidades metacognitivas. En el año del 2005 el curso fue estructurado e implementado a partir de los resultados observados en el curso del 2004. Como resultado final se confirmó que el número de actividades realizadas por los alumnos creció en el curso del 2005. Los informes de los alumnos se tornaron más detallados y con una mayor cantidad de información descrita. Palabras clave: Creatividad; Conocimiento; Aprendizaje. 


\section{Introduction}

In recent years, creativity education in universities has extensively incorporate project-based classroom practices aimed at fostering a creative attitude in learners through experience in production activities (Elata \& Garaway, 2002; Hirose, 200I). The goal of these classes is to have the learners acquire creative attitudes and engineering knowledge by developing ideas through group discussions, and by giving concrete form to those ideas.

As an example of this approach, we have attempted to incorporate such creative education practices into education targeting university students (Ishii \& Miwa, 2005). Specifically, we divided students into groups, and put to them the challenge of creating a robot using LEGO Mindstorms. As a result, we confirmed that the students were able to learn through experience the importance of "Thinking" and "Using one's hands" in the context of creative production activities.

In this way, creative education in engineering education involves the accumulation of know-how through practice. Many of these activities, however, are attempts at investigation based on the educational experiences of teachers. It is important to examine class design and evaluation methodologies; for example, from the following perspectives: "How classes should be configured to ensure the most effective learning?" or "How should practical results be evaluated, and how should these evaluations be used to further improve the classes?

In the current study, we propose a framework for achieving more effective design, execution, and evaluation of creative education in engineering education.

The framework consists of the following three components.

\section{Instructional design based on knowledge from psychology}

Up to now, many attempts at creative education have involved classes designed based on the experiences of the teachers. By contrast, the framework proposed here actively incorporates knowledge from psychology in relation to education and learning in addition to the experiences of the learners, in order to achieve more effective classes. Based on this approach, we then designed classes that can be expected to demonstrate better results in terms of learning.

\section{Development of systems for supporting creative activities}

In the field of software engineering, many systems have been developed to support "Thinking activities" in the context of creative activities. In real situation, people learn a great deal from trial and error, in the repeated process of creating and evaluating prototypes. In the framework proposed here, we have developed a creative activity support system that focuses on "Production activities" and "Evaluation activities," and have introduced this system into a class environment.

\section{Objective evaluation of learning results related to creativity}

A large number of the creative education practices mentioned above involve subjective evaluations of class results based on questionnaires. Furthermore, these questionnaires are limited to qualitative evaluations of the changes in the learners with regard to creativity. In order to gain a detailed understanding of what the learner specifically learned with regard to creativity, however, it is necessary to conduct evaluations based on objective data; for example, changes in knowledge and skills related to creativity. In the framework proposed here, we will objectively evaluate learning results by establishing items that will enable evaluations of increases in skills related to creativity.

The purpose of this research is to design classes based on the above framework, and through its practice, to clarify its effectiveness. Based on this framework, we designed creative education classes for engineering education. We put these classes into practice for one half of an academic year targeting first-year engineering students, and conducted evaluations and observations of the learning results. 


\section{Designing Learning Environments for Creativity}

When designing classes, it is necessary to set learning objectives. In the practice of creative education up to now, there have been objective goals with regard to contents, but the learning objectives with regard to creativity have been abstract.

In this research, we set as the learning objectives "improving idea generation skills in creative activities." Specific perspectives for evaluations were "Number of ideas (volume of idea generation)"; "Scope of ideas (variation in the ideas generated)"; and "Depth of ideas (depth of study regarding a single idea)." Based on these perspectives, we then objectively evaluated the degree to which the students' idea generation skills changed.

These evaluation perspectives correspond to the "Creativity Factors" proposed by Guilford - "Fluent thinking (volume of ideas produced)"; "Flexible thinking (the ability to produce a wide range of different ideas)"; and "Elaborative thinking (the ability to specifically elaborate on and complete the idea)" and are considered appropriate indexes for measuring creativity in learners (Guilford, 197I).

\section{Applying knowledge from psychology}

In these classes, we actively incorporated knowledge of psychology in relation to education and learning in order to achieve more effective classes. In the classes, we focused on knowledge from psychology related to meta-cognitive activities in creative activities.

The field of learning sciences, which studies human learning processes in educational situations points out the importance of "meta-cognition" in which the learner's own activities in an educational or learning situation are seen from a "meta" perspective (Bransford, Brown \& Cocking, 2005; Brown, 1987; Chi, Bassok, Lewis, Reimann \& Glaser, 1989). In fact, empirical studies have confirmed that meta-cognitive activities promote learning in various domains such as physics education (Chi, Leeuw, Chiu \& LaVancher, 1994) and programming education (Bielaczyc, Pirolli \& Brown, 1995). Furthermore, in the field of design education, the importance of meta-cognitive activities such as self-reflection has also been suggested (Schön,
1987), and some practical studies that intended to foster reflective activities in design have been conducted (Adams, Turns \& Atman, 2003; Oxman, 1999).

Among the various types of meta-cognitive activities, the authors' prior research into the practice of creative education suggested the effectiveness of "reflection" in particular - the activity of looking back at one's own activity processes (Ishii \& Miwa, 2005). In the classes in the current study, we incorporated this meta-cognitive activity of "reflection" into the classes as well.

\section{Setting learning phases}

\section{The educational program consisted of three main phases.}

Phase I: Introduction

As an environment for creative learning activities by learners, put in place a programming environment comprised of a laptop PC for each student, and have the learners acquire basic knowledge of LEGO Mindstorms and relevant programming language.

Phase 2: Experiencing creative activities

Learners form pairs, working together to produce a robot (the creative activity set as the theme for the class); they then participate in a "time trial" competition. The competition is a race comprising one lap of a course. The learners are required to produce a robot that avoids obstacles and has a function that traces a line where it has moved.

During these activities, the learners regularly record the status of their own pair's progress (robot's shape, robot's movement, race results, control program, and comments). These status reports are re-corded using the creative activity support system described in the following section.

\section{Phase3: Reflection}

After the creative activities, learners undergo "Reflection" to deepen their understanding and awareness of their own creative activities. Learners 
summarize their groups' creative processes in a chart using a piece of paper measuring about $2 \mathrm{~m} \times \mathrm{Im}$ (hereinafter referred to as the "Reflection Sheet"). The Reflection Sheet is divided in half, from top to bottom. On the top half of the sheet, the learners position the PAD (Problem Analysis Diagram) and the program source on a timeline (a software element), and on the bottom half of the sheet, they place a photo of the robot (a hardware element). PAD is a method of diagramming ways of thinking (algorithms) when programming. When programming, it is fundamental to schematize the algorithm of the processing in advance, and then write code based on the schematic.

As a supplementary explanation for these materials, at each stage of the creative activities, the learners write on the sheets (I) what they are planning and (2) what results they achieved (Figure I). The materials used for placement on the Reflection Sheet are the items recorded in the creative activity support system.

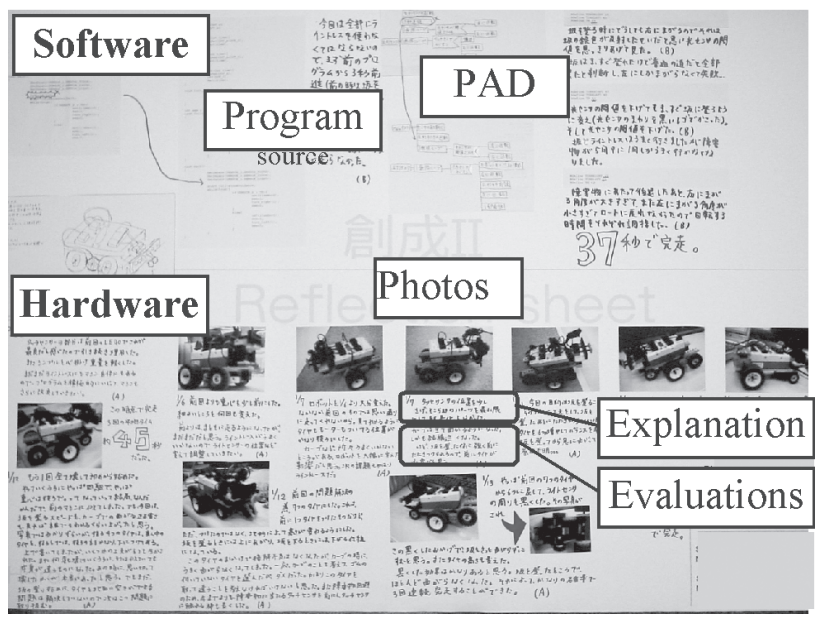

Figure I. Example of reflection sheet (2004).

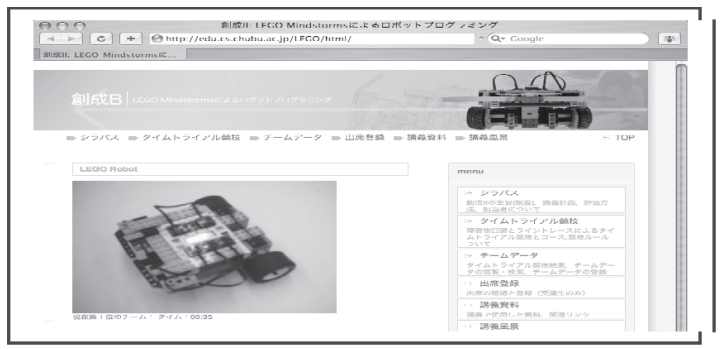

Top page
Creative activity support system

In the classes in the current study, we incorporated the meta-awareness activity of "reflection." During Reflection, by looking back at the process of trial and error in their own learning activities, the students learn many things. At this time, in order to ensure that the learners gain a detailed understanding of their own creative activities, it is necessary to regularly record the details of the activities conducted as part of creative activities. Furthermore, when creating the robot, it is necessary to undertake "version management" of both the software and hardware elements over a long period of time.

In this study, we therefore developed a creative activity support system that would enable recording, management, and viewing of the groups' creative activities, to provide support for the learners' "Reflection" activities. This web-based system, which is comprised of a PHP linked with a database (MySQL), enables the learners to upload any items related to the group's creative activities using a browser (Figure 2).

The information recorded by the learners is updated in real time, so the learners can check the ranking status of their own or other learners' teams at any time. Using this system, the learners regularly record the status of their groups' activities. They then create the Reflection Sheet while viewing their own creation processes, which they have recorded in the system, and downloading the appropriate data as required.

\section{Evaluation of learning results}

We conducted an actual class in creative education; a course held in the Autumn Term in the 2004

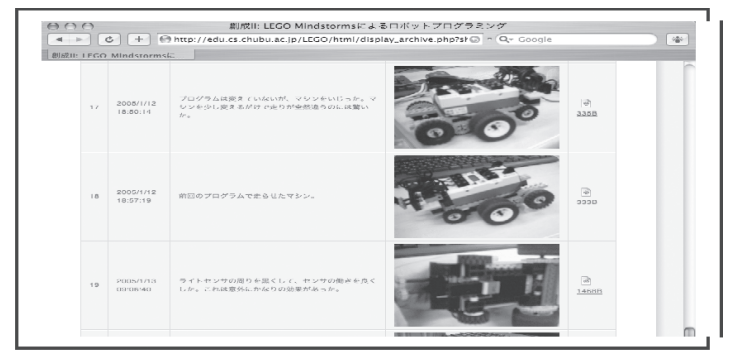

Learners' creative processes

Figure 2. The creative activity support system (2004). 
academic year at the Chubu University College of Engineering. The learners included |3| first-year students in the College of Engineering Department of Computer Science. The curriculum for this course lasts for 13 weeks, with each (weekly) class lasting 135 min.

In these classes, in order to evaluate the learning results for skills related to the learners' creativity, we presented design tasks before and after the classes, based on an arrangement of Finke's "invention tasks (Finke, 1990I)." A total of 91 students participated in the design tasks. The students were given sheets that presented with I 5 specific types of parts, such as cube, wire, and wheels, and were asked to come up with new ideas for arranging these parts in any way that they pleased, sketching their ideas on a piece of paper one at a time. Each of the students was randomly assigned one of three themes for these ideas: "Playground equipment," "Furniture," and "Stationery." They were also given a 20-minute time limit.

First, we categorized the ideas generated by the students according to the functions of each idea.
Specifically, Author I categorized the responses according to the respective themes(Table I).

\section{Changes in learners' idea generation skills}

First, we evaluated the changes in idea generation skills during creative activities, which were set as the learning objective in these classes. In this paper, we calculated these changes based on the variations in the functions of the ideas; that is, the "Scope of ideas." Similarly, we expressed the "Depth of ideas" as the maximum value for the depth of study regarding an idea with a single function.

From the results of these evaluations, we confirmed that the number of ideas generated increased after the classes as compared to before $(\mathrm{t}(90)=4.48 \mathrm{I}, \mathrm{p}<.0 \mathrm{I}) \quad$ (Figure 3$)$. We also confirmed that both the scope $(\mathrm{t}(90)=3.727$, $\mathrm{p}<.0 \mathrm{I})$ and depth $(\mathrm{t}(90)=2.629, \mathrm{p}<.05)$ of the ideas generated increased after the classes were completed. The above results suggest that the students learned idea generation skills through these creative activities.

Table I. The categories of ideas.

\begin{tabular}{clllll}
\hline Themes & \multicolumn{5}{c}{ Categories } \\
\hline $\begin{array}{c}\text { Playground } \\
\text { equipment }\end{array}$ & Ride & Spin & Hang & Slide & Go in \\
& Go across & Swing & Run & Climb & Throw \\
\multirow{2}{*}{ Furniture } & Store & Hang & Carry & Organize & Place \\
& Sit & Clean & Sleep & Light up & Cook \\
\hline \multirow{2}{*}{ Stationery } & Store & Write & Erase & Cut & Stick \\
& Draw & Measure & Hold & Clean & Record \\
\hline
\end{tabular}

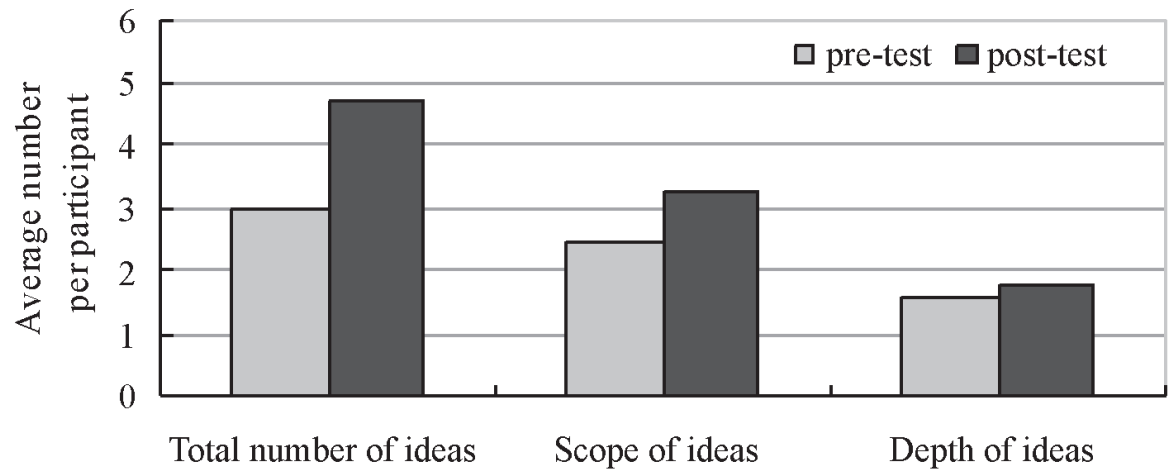

Figure 3. Changes in Students' idea generation skills (**: $p<.01, *$ : $p<.05)$. 
Changes in behavior related to learners' reflections

Next, we analyzed the extent to which the learners underwent autonomous reflection through the Reflective Activities introduced into the classes.

We tabulated the number of learners who underwent Reflective Activities in terms of "Re-examining ideas with functions that were thought of before" in the context of design tasks, and confirmed that when thinking of ideas, the ratio of learners who re-examined the functions they thought of before increased from about 19\% to about $38 \%\left(\chi^{2}(I)=8.723, p<.0 I\right)$. Although this is only a small ratio of the entire group of learners, these results indicate that the number of learners who undertook autonomous reflection in creative activities increased as a result of having experienced Reflection in the classes.

From these results, we can say that the education in creativity implemented by the course improved the students' creative endeavors. However, some challenges remained.

First, although the goal of the course was to foster a creative mindset, the actual lessons also taught programming skills at the same time. In 2004, we did not evaluate programming skills. Also, we prepared a system that each team could use to archive their activity data as an aid for the reflection activity. However, there was great variation in the frequency of their archival updates, and it is difficult to say that they made sufficient use of the system. Also the archived contents did not cover all the records of the activities by the groups and students. Furthermore, we believed that we needed to improve the format of the reflection sheet for it to better serve as a tool for the students to review their activities.

Thus in the 2005 academic year, we implemented the course as follows to grapple with these challenges.

\section{Improving Learning Environments for creativity}

This section gives a report of the 2005 course as it was carried out. We especially describe the content of the improved course design as it relates to the points raised by the evaluation of the 2004 course. The name of the course was changed to "Creation B" in 2005, but it is essentially the same course as 2004 . The course was lengthened to 15 weeks from 13 weeks.

\section{Improvement I: PAD assignment}

The 2004 evaluation raised the point that results of the goal of acquiring of programming skills were not evaluated. To address this issue, PAD assignments were added to the course content in 2005.

When improving a program, it is critical not to modify the code directly, but instead, to review one's way of thinking by re-examining the algorithm. In 2005 course, we evaluated the learning results that come from using PAD. We designed the PAD assignments as follows.

The assignments were given as a pre-test in the fifth class, which is the class before the start of creative activities. They were also given assignments as a posttest in the 12th class, which is the class after the end of creative activities. An assignment consists of three problems: one basic problem concerning robot programming, the target of this course, and two problems concerning the mechanisms of automatic vending machines (one basic, one applied). The students draw diagrams of algorithms for each problem using PAD on their answer sheets. An example of a student's answer (in the fifth class) is given in Figure 4. The students were given a time limit of 40 minutes to complete the problems.

\section{Improvement 2: Activity reports}

We made creating activity reports and archives mandatory as aids for the reflection activity. For the activity reports, the students must record the number of hours spent and the number of times they ran their programs, the PADs of their created programs, and comments.

By making these records mandatory, we sought to address the problem found in the 2004 survey that showed that the teams varied greatly in how often they updated their archives.

Also, the recordkeeping allowed students to understand their own activities in greater detail when 


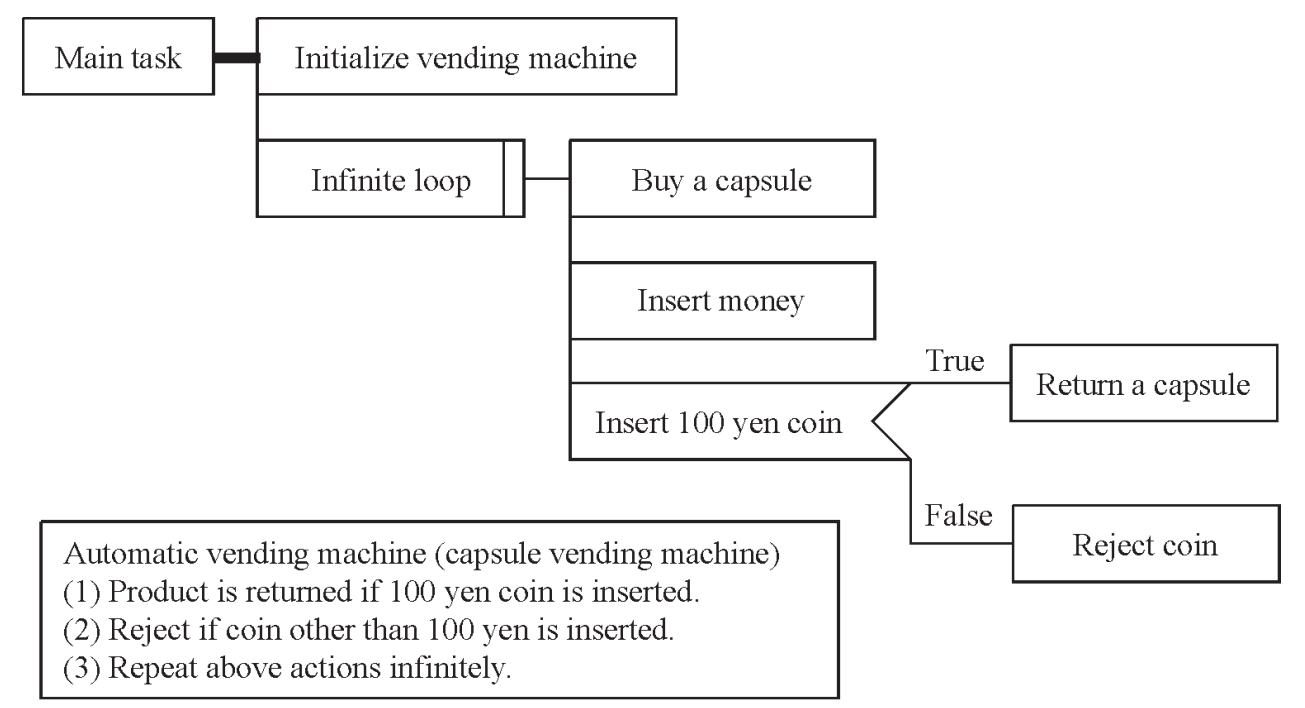

Figure 4. PAD assignment and sample answer.

making reflection sheets. It also served to habituate them to a basic practice of engineers, which is to keep successive records of their activities.

Also, from the records the educational staff could understand the amount of time spent by students outside of class on the assignments, as well as the number of trials. Thus useful information could be obtained for the evaluation of the course.

\section{Improvement 3: Format of reflection sheet}

The reflection sheet was changed from the 2004 format, which had two entry columns, one for software and one for hardware. The new design allowed entries in three sections: Plan, Do, and See.

The PDS cycle is a synonym for the PDCA cycle, which is a management method for operations to continually maintain and improve their quality. The $\mathrm{P}$ (plan) $\mathrm{D}$ (do)C(check)A(act) cycle is more general, but for this course, the PDS cycle was used because we believed it is easier for students to understand.

We believe making engineering students keep records using the PDA cycle is effective for them to realize that this method is used even in actual manufacturing sites. Also, having the students' record what was done under which part of the cycle is useful for providing data to judge objectively their improvements in creativity. Thus the reflection sheets employed these changes in design.
To distinguish between contents about software and hardware, which were separated in 2004, entries were made using different colors. Also, to indicate which member of the team was mainly responsible for what activity, entries were marked with an "A" or a "B" in the same manner as in 2004.

An example of a reflection sheet using the modified format is shown in Figure 5.

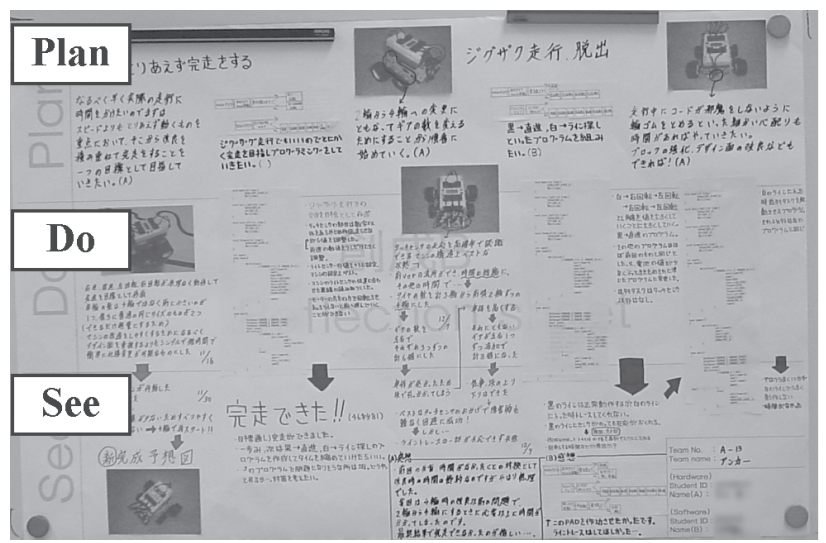

Figure 5. Example of reflection sheet (2005).

\section{Improvement 4: Student's role}

From the contents of the 2004 reflection sheets, it could be seen that the teams internally split into two fixed roles, with one member responsible for the programming and one responsible for the robot. To address this situation, instructors explained the two 
roles beforehand to raise awareness in students, and during Phase 2 of the second course, students were told to switch the roles once. Students were told that the roles were not divisions of labor, but rather cooperation with members deciding who will be mainly in charge of what.

\section{Improvement 5: Creative activity support system}

The creative activity support system was changed to support the changes in the design of the 2005 course (described above). Figure 6 shows the updated system. For the activity reports, handwritten files were converted to PDF format, which made archiving more efficient.

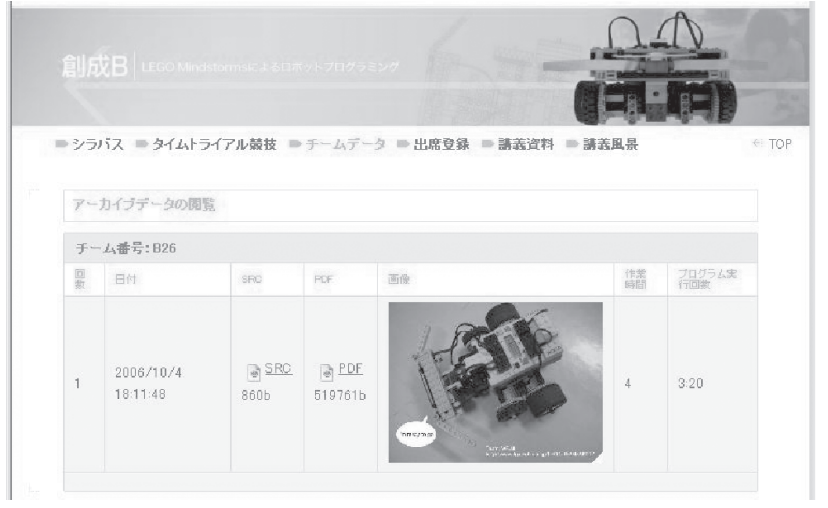

Figure 6. The creative activity support system (2005).

\section{Results and Discussion of Improving Learning Environments}

The section reports the evaluation of the learning results implemented in the 2005 academic year. We especially focus on the three points of improvement described above: the implementation of the PAD assignment, the creation of the activities report, and the change in the format of the reflection sheet.

\section{Analysis of PAD Assignment}

We now describe the results of the analysis of the PAD assignment given in 2005. The subjects were 105 students present of the 133 students enrolled in the course. We give the results of the analysis of the application question, which had the highest degree of difficulty of the three questions in the PAD assignment.

We used a count of the number of algorithmic units in the students' responses as an indicator of the complexity of their algorithms. In the students' answers, if the PAD format was not satisfied or if the solution does not work, the unit count was considered zero.

The results showed an average of 8.9 units for the pre-test and 10.6 for the post-test. The number of units increased after the course compared to before the course. The t-test confirmed a significant difference $(t(104)=2.648, p<.01)$.

From the above results, we confirmed that the students' skills in constructing algorithms increased through the course's robot programming activities.

\section{Results of activity reports}

The effects of the archive report activity, which was made mandatory from 2005, are summarized below. This report was added because of the criticism in 2004 evaluation that teams showed great variance in their number of their archival data uploads and were not using the archives effectively.

Figure 7 compares the number of uploads between the 2004 course and 2005 course. The average number of uploads for the 2004 course was 8.14 and for 2005 course 9.49 , indicating an increase. The distribution has also narrowed $(t(|| 5)=1.795$, $\mathrm{p}<.10)$. Thus a certain level of improvement could be seen.

\section{Analysis of Reflection Sheet}

As described above, the reflection sheet used in 2005 was changed to allow entries during the three stages of Plan-Do-See cycle. To evaluate the contents, we measured the amount of information as described below.

For the measuring criterion, we used not the places where entries were made, but gave first priority to the contents. We counted the pieces of content that fall into the categories of the Plan-Do-See cycle and software/hardware. If a sentence included multiple contents, then the sentence was divided and each piece 

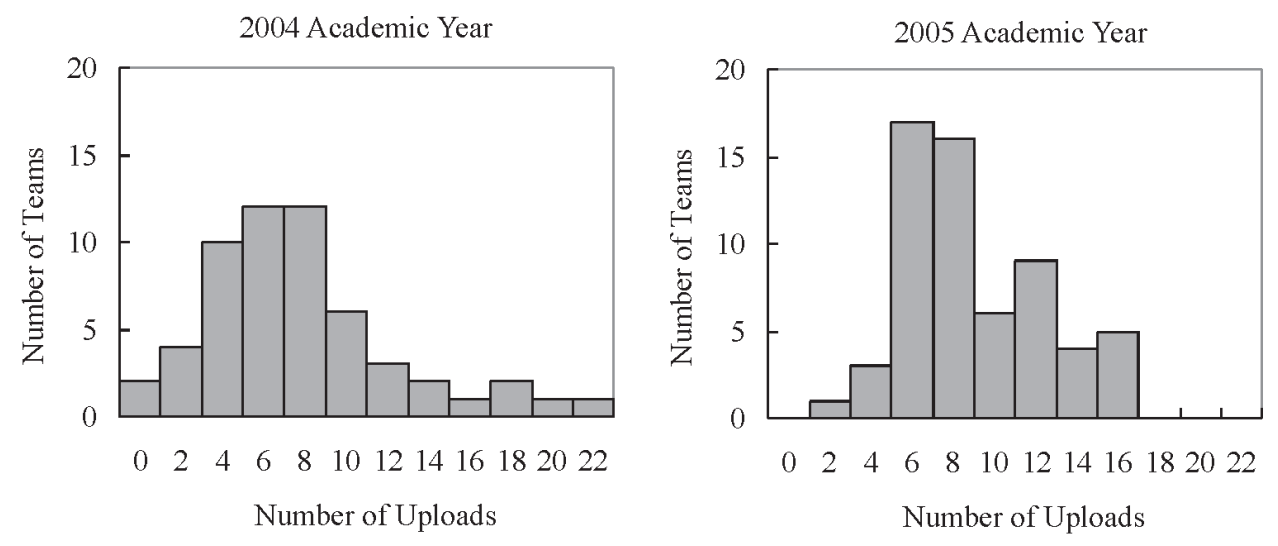

Figure 7. Frequency of uploads of activities data.

of content was counted. For example, the sentence "We modified the placement of the sensor, and made it lighter" included two pieces of contents, so it was divided and each piece counted separately. Based on the above method of measurement, the average number of pieces of contents for each category in 2005 compared to 2004 is shown in Figure 8.

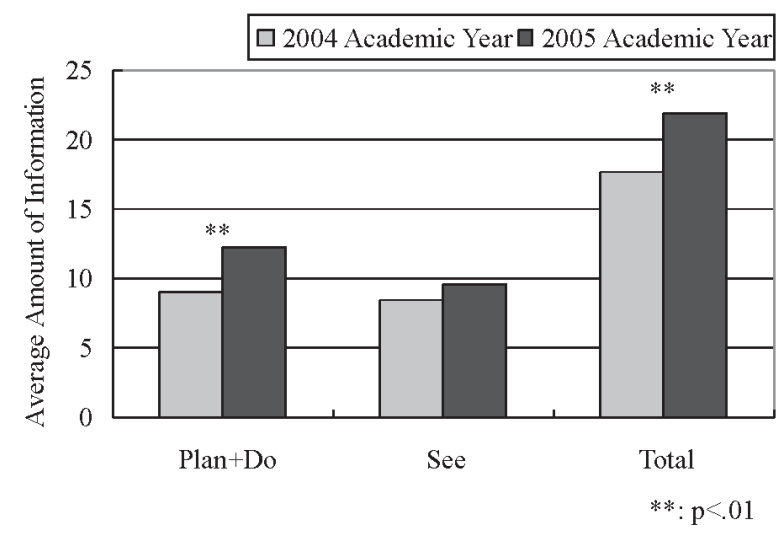

Figure 8. Comparison of average amount of reflection sheet information.

From the above results, we can see that the average of the total count for the "Plan" and "Do" category has increased $(t(I \mid 3)=3.255, p<.0 I)$. This indicates that the records of "what kinds of things were planned" and "what was done" have increased. However, the average of the total of "See" category, which indicates "how were the results?", did not show a significant difference $(t(I \mid 3)=I .565$, n.s.). For the average of the total count of all the categories, there was an increase $(t(I \mid 3)=2.963, p<.0 I)$.

\section{Discussions}

From the above analyses, we see that the number of uploads of activity data from students have increased in the 2005 course. The reflection sheets have also become more detailed and their volume of information have increased. These changes were due to making these activities mandatory, and as a result, they made it possible for the students to record the contents of their activities more easily and in greater detail. For the PAD assignments, we only measured using a criterion of quantity, and saw some positive results. Further analysis in greater detail is necessary.

In this section, on the basis of the results of our educational program, we discuss how we should design and improve a learning environment to foster creative attitudes.

\section{Scaffolding to Support Creative Activities}

Using Mindstorms as a tool enables learners to consider and embody their ideas relatively easily; nevertheless, constructing products using Mindstorms requires learners to have basic mechanical knowledge such as how to construct a mechanism and how to program an algorithm. In such a situation, a teacher has to provide the learners with basic knowledge of Mindstorms and step-by-step exercises before they can engage in creative activities. In our educational program, we provided the learners with scaffolding to experience creative activities. Scaffolding is an external support that enables a learner to achieve a 
goal that could not otherwise be reached. In the field of learning science, the importance of scaffolding for learners' activities has been discussed (Hmelo, Holton, \& Kolodner, 2000; Linn \& His, 2000).

In our educational design, we gave the learners step-by-step goals for their creative activities, such as acquiring basic knowledge of Mindstorms and constructing a simple four-wheeled car (Phase I), before they attempted the main task (Phase 2). Moreover, we conducted the cycle of activities in Phase 2 (Experiencing creative activities) and Phase 3 (Reflection) twice. In the second cycle of creative activities, we had the learners completely dismantle the robots produced in the first cycle, to encourage them to take on the challenge of creating new ideas. In such experience-based creativity education, a teacher should provide the learners with not only a goal but also scaffolding that encourage creative activities.

\section{Providing Information on Creative Processes}

In this study, we designed and conducted classes that introduced the practice of "Reflection." We confirmed that the results demonstrated the effectiveness of these classes, in terms of increasing the volume, scope, and depth of the ideas created by the learners in the idea generation tasks after the classes were complete. In such activities, if the learners had been given no information on their processes, they would have forgotten their own detailed processes and reflected on incorrect processes. Hershkowitz and Schwarz (1999) confirmed such a phenomenon, referred to as purification, in their educational program in mathematics.

In our educational program, the learners regularly recorded the status of their own pair's progress, and they created the Reflection Sheet while viewing their own creation processes, which they have recorded in the creative activity support system, and downloading the appropriate data as required. By doing so, they could correctly reflect on their creative processes in detail. We found that setting "Reflection" as one of the learning activities stimulates activities such as gaining a detailed understanding of one's own creative processes, correcting mistaken memories, and sharing knowledge with other group members, and that this in turn leads to increased quality in learning results.

In terms of areas for future improvements, in the field of learning sciences, it has been pointed out that in order to support Reflection, it is important to clearly show the learning content and learning processes (Process Displays), to encourage explanations and evaluations of the activities in question (Process Prompts), to propose ideal models (Process Models), and to promote social dialogue (Social Discourse) (Lin, Hmelo, Kinzer \& Secules, 1999). The system we have created incorporates a process presentation function in which the learners' creative activities are shown a list. In the future, we would like to add to the system learning support functions targeting other activities as well.

\section{Conclusions}

In this study, we propose a framework for designing and improving learning environment for creativity in engineering. Based on that framework, we conducted an actual class in creative education; a course held in the Autumn Term in the 2004 academic year at the Chubu University College of Engineering. As a result, we confirm the following two educational effectiveness of our framework:

We designed and conducted classes that introduced the practice of "Reflection." We confirmed that the results demonstrated the effectiveness of these classes, in terms of increasing the volume, scope, and depth of the ideas created by the learners in the idea generation tasks after the classes were complete.

We constructed a creative activity recording support system as a system for supporting the learners Reflection activities. Using this system, the learners were able to centrally record and manage details of the groups' activities via the Internet.

In the 2005 academic year, we improve the course based on 2004 results. By implementing the improvements, we were able to see an increase in the amount of recordkeeping of the students' own activities and improvements in creative activities 
compared to the 2004 course. In the future, we plan to further analyze the effects of cooperative work on creative activities, and to incorporate the analysis in the improvement of this course.

\section{References}

Adams, R. S., Turns, J., \& Atman, C. J. (2003). Educating effective engineering designers: The role of reflective practice. Design Studies, 24(3), 275-294.

Bielaczyc, K., Pirolli, P. L., \& Brown, A. L. (1995). Training in self-explanation and self-regulation strategies: Investigating the effects of knowledge acquisition activities on problem solving. Cognition and Instruction, I3(2), 22 I-252.

Bransford, J. D., Brown, A. L., \& Cocking, R. R. (1999). How people learn: Brain, mind, experience, and school. Washington, D.C.: National Academy Press.

Brown, A. L. (1987). Metacognition, executive control, selfregulation, and other more mysterious mechanisms, In F. E. Weinert \& R. H. Kluwe (Eds.), Metacognition, motivation, and understanding. Hillsdale, NJ: Lawrence Erlbaum Associates.

Chi, M. T. H., Bassok, M., Lewis, M. W., Reimann, P., \& Glaser, R. (1989). Self-explanations: How students study and use examples in learning to solve problems. Cognitive Science, 13(2), 145-182.

Chi, M. T. H., de Leeuw, N., Chiu, M., \& LaVancher, C. (1994). Eliciting self-explanations improves understanding. Cognitive Science, 18(3), 439-477.
Elata, D. \& Garaway, I. (2002). A creative introduction to mechanical engineering. International Journal of Engineering Education, I8(5), 566-575.

Finke, R. A. (1990). Creative imagery: Discovery and inventions in visualization. Hillsdale, NJ: Lawrence Erlbaum Associates.

Guilford, J. P., \& Hoepfner R. (197I). The Analysis of Intelligence. New York: McGraw-Hill.

Hershkowitz, R., \& Schwarz, B. B. (1999). Reflective processes in a mathematics classroom with a rich learning environment. Cognition and Instruction, I 7(I), 65-9I.

Hirose, S. (200I). Creative education at Tokyo Institute of Technology. International Journal of Engineering Education, I 7(6), 5|2-5|7.

Hmelo, C. E., Holton, D. L., \& Kolodner, J. L. (2000). Designing to learn about complex systems. The Journal of the Learning Sciences, 9(3), 247-298.

Ishii, N., \& Miwa, K. (2005). Supporting reflective practice in creativity education. Proceedings of Creativity \& Cognition 2005 , April 12-15, (pp. 150-157), London: ACM Press.

Lin, X., Hmelo, C., Kinzer, C., \& Secules, T. (1999). Designing technology to support reflection. Education Technology Research and Development, 47(3), 43-62.

Linn, M. C., \& Hsi, S. (2000). Computers, Teachers, Peers: Science Learning Partners. Mahwah, NJ: Lawrence Erlbaum Associates.

Oxman, R. (1999). Educating the designerly thinker. Design Studies, 20(2), I05-122.

Schön, D (1987). Educating the reflective practitioner. San Francisco, CA: JosseyBass.

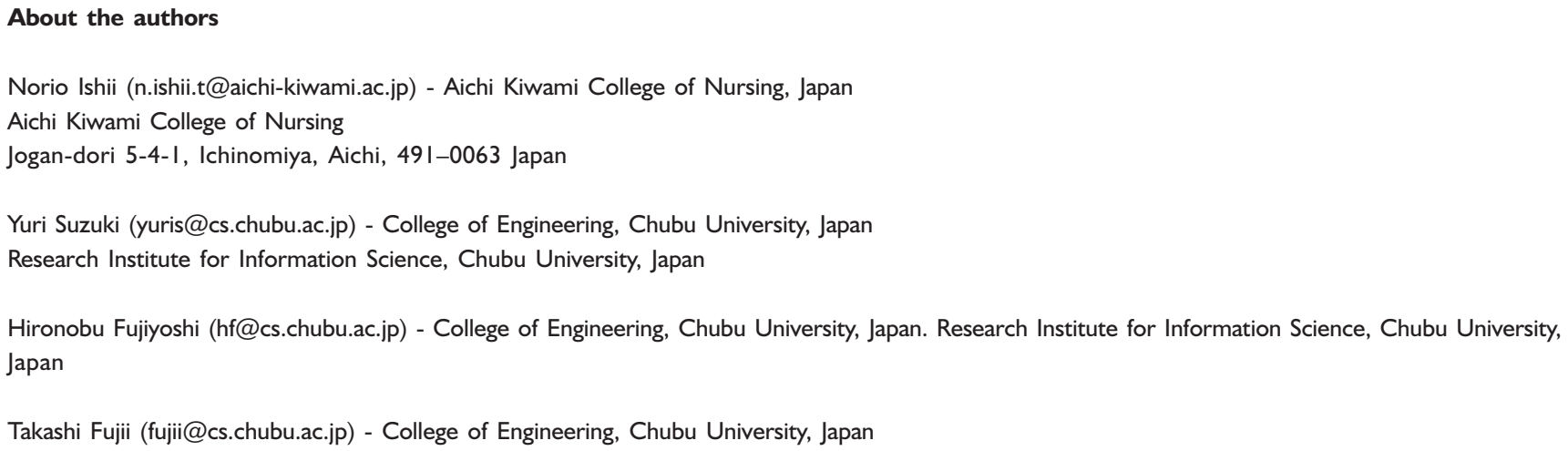

